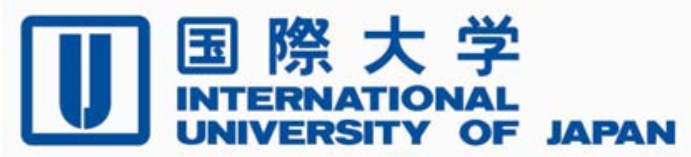

Economics \& Management Series

EMS-2014-09

\title{
Labor donation or money donation? Pro-sociality on prevention of natural disasters in a case of cyclone AILA, Bangladesh
}

Shibly Shahrier

International University of Japan

Koji Kotani

International University of Japan

June 2014

IUJ Research Institute

International University of Japan

These working papers are preliminary research documents published by the IUJ research institute. To facilitate prompt distribution, they have not been formally reviewed and edited. They are circulated in order to stimulate discussion and critical comment and may be revised. The views and interpretations expressed in these papers are those of the author(s). It is expected that the working papers will be published in some other form. 


\title{
Labor donation or money donation? Pro-sociality on prevention of natural disasters in a case of cyclone AILA, Bangladesh
}

\author{
Shibly Shahrier* Koji Kotani ${ }^{\dagger}$
}

June 29, 2014

\begin{abstract}
The coastal zone in Bangladesh is the most powerfully lethal due to cyclones and storm hazard where $29 \%$ of the total population reside. Thus, collective disaster mitigation measures are urgent, and it is important to understand people's pro-social attitude toward such countermeasures. However, few studies on this issue have been conducted in the context of developing countries, such as Bangladesh, and we therefore address this issue. We made a questionnaire survey of 1,000 respondents and elicited (i) a willingness to donate their labor (WDL) and (ii) a willingness to pay (WTP) to collective countermeasures for avoiding the damages from cyclones and associated disasters. With this data, we examine WDL and WTP in relation to respondents' occupation, education and income. The novelty lies in offering respondents an option of choosing WDL and/or WTP in the questionnaire. The study finds that the poor and less educated people are likely to choose WDL and willing to donate more labor, while rich and educated people are likely to choose WTP and willing to donate more money. However, we also find that voluntary labor donation from poor and less educated people is significant in that overall donation from poor and less educated people exceeds that from rich and educated people. Overall, poor and less educated people may be more pro-social and WDL is an important source of contribution to be utilized in natural disaster mitigation of developing countries. This finding can be considered a useful guidance for future policies in more general cases, since it is consistent with observed labor donations for the recovery in the 2011 earthquake off the Pacific coast of Tohoku, Japan.
\end{abstract}

Key Words: Pro-sociality; natural disaster; preventive measures; willingness to pay; willingness to donate labor;

\footnotetext{
*International University of Japan

${ }^{\dagger}$ Professor, Graduate School of International Relations, International University of Japan, 777 Kokusai-cho, MinamiUonuma, Niigata 949-7277, Japan (e-mail: kkotani@iuj.ac.jp)
} 


\section{Contents}

$\begin{array}{lr}\text { Nomenclature } & 3\end{array}$

1 Introduction $\quad 4$

2 Cyclone AILA and our study region $\quad 7$

3 Data and methodology $\quad 10$

4 Results $\quad 13$

4.1 Socio-economic characteristics of respondents . . . . . . . . . . . . . . 13

4.2 Preliminary results on WDL and WTP . . . . . . . . . . . . . . . . . . . . . . . . .

4.2 .1 WDL and WTP . . . . . . . . . . . . . . . . . 15

4.2 .2 Aggregated WTP . . . . . . . . . . . . . . . . 16

4.3 Pro-sociality toward disaster mitigation in relation to occupation, education and income . . . . . . . . . . . . . . . . . . 17

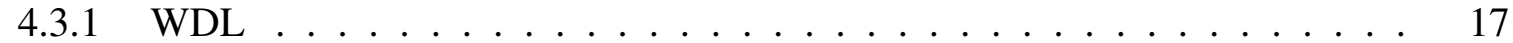

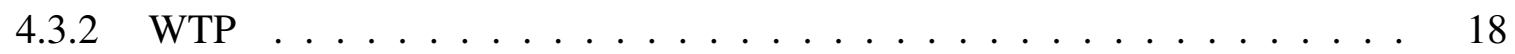

$4.3 .3 \quad$ Aggregated WTP . . . . . . . . . . . . . . . . . . 19

5 Discussion and conclusion $\quad 21$

6 Bibliography $\quad 24$

$\begin{array}{ll}\text { List of Tables } & 27\end{array}$

$\begin{array}{ll}\text { List of Figures } & 34\end{array}$ 


\section{Nomenclature}

BDT Bangladeshi taka (1 USD $\approx 75$ BDT, May 10th, 2014)

CVM Contingent valuation method

WDL Willingness to voluntarily donate labor

WTP Willingness to pay 


\section{Introduction}

On 25th May, 2009, cyclone AILA, which is a category-1 super cyclone, hit the coastal areas of Bangladesh and caused huge damage to people and their life. Following the cyclone, storm surges flooded the areas which provoked most of the damages and resulted in long-term salinity problems for cropland and sweet water sources. Unfortunately, such a cyclone is a common natural disaster in Bangladesh. Every year, on the average, 3.48 storms strike Bangladesh (Ali, 1996). It has also been reported that the frequency of intense cyclones in north Indian Ocean and the sea surface temperature has increased due to global climatic changes (Singh et al., 2001, Khan et al., 2000). The sea level rise is another major threat for the coastal people of Bangladesh, because it magnifies the intensity of cyclones as well as the tidal surges (Khan et al., 2000). Bangladesh is scientifically predicted to experience more intense and frequent cyclone storms in the future.

Cyclone AILA is the latest super cyclone which Bangladesh has experienced. Due to its massive long term effect, the memories of this event are still alive in people's mind. The tidal surges followed by AILA was gigantic. The immediate impacts resulted in 90 deaths and 7,100 injuries, and 3.9 million people were affected (United Nation, 2010). Moreover, it destroyed infrastructures and some other forms of public goods, such as embankment, educational and government institutions, roads, crop land, shrimp-ghers ${ }^{1}$ and fisheries. Water and land salinity has been prolonged up to now due to water stagnation that could be considered a special feature associated with cyclone AILA. For example, the people in Satkhira and Khulna districts of Bangladesh have been still suffering from a high level of water and land salinity.

Given the occurrence of cyclone AILA and expected threats of more intense and frequent cyclones in the future, it is necessary to take collective long-term hazard mitigation to protect the coastal people in Bangladesh. For this, local people's voluntary contributions have been claimed to be a major issue and an essential component in the process of planning and implementation of mitigation measures, since disaster management cannot be sustainable without having people's prosocial behaviors ranging from prevention to recovery (Mileti, 1999, Dorcey and McDaniels, 2001,

\footnotetext{
1 "Shrimp-gher" is a special pond for shrimp cultivation in the coastal regions of Bangladesh.
} 
Godschalk et al., 2003, Pearce, 2003). Therefore, this paper examines how people are pro-social or cooperative toward the mitigation measures against cyclones or related natural disasters by considering a case of cyclone AILA.

Past research analyzes the degree of pro-sociality in several different ways. One method is eliciting their willingness to pay (hereafter, WTP) using contingent valuation method (hereafter, CVM) (see, e.g., Mitchell and Carson, 1988, Alberini and Kahn, 2009). Most of the CVM studies have been conducted to quantify the required compensation or damage caused by environmental deterioration (see, e.g., Carson et al., 2003, Cooper et al., 2004, Martin-Ortega et al., 2011). On the other hand, other different types of studies have used elicited perceptions to environmental problems or have examined actual contributions to publicly organized programs for improving the quality of environmental or public goods as measures of pro-sociality (see, e.g., Menchik and Weisbrod, 1987, Wolff et al., 1993, Smith, 1994, Frey and Meier, 2004, Torgler et al., 2009).

Irrespective of specific approaches employed in the aforementioned studies, a positive and significant correlation between pro-sociality and income or between pro-sociality and education is found. For instance, Freeman (1997), Kontogianni et al. (2001), Vanslembrouck et al. (2002), Bienabe and Hearne (2006), Plagnol and Huppert (2010) and Martin-Ortega et al. (2011) illustrate such positive correlations of WTP, willingness to participate in publicly organized programs or WDL with income and education. In particular, Kemmelmeier et al. (2002) claim that the level of pro-social behavior measured by voluntary participation in publicly organized programs is positively correlated with income and education, because poor and less educated people need to focus on their own life and families' material welfare. As a result, such people do not have any room of time and money to contribute.

Although the positive association is established in many studies, there are a few studies reporting that the positive relation may not be true. Brechin and Kempton (1994) report that people in developing countries may be more pro-social toward environmental protection even when the degree of pro-sociality is measured by monetary contribution. They also suggest some possibility that people in developing countries may practically contribute more to environmental protection if we consider the option to donate their voluntary labor as a part of contribution. Similarly, Godschalk et al. (2003) 
have also found that education does not positively influence WTP for global environmental issues.

In the context of natural disaster mitigation, there are only a few works that identify pro-sociality focusing on voluntary monetary payment or voluntary participation toward collective disaster mitigation. Recently, voluntary contributions of local people are claimed to be very important to ensure the sustainability of disaster mitigation as well as continuous development of the regions (see, e.g., Pearce, 2003, Godschalk et al., 2003). Markantonis et al. (2013) apply the CVM to elicit WTP for avoiding the damage of severe flooding and find that experts and hunters are willing to pay more than farmers. Luo and Levi (2013) analyze the determinants to induce participation in collective disaster reduction programs. They report that farmers usually pay a lot of attention to the non-engineering practices, but willingness to participate is low, and that education and professional skills can influence the decision to participate or not. Ghanbarpour et al. (2014) apply CVM to evaluate people's cooperative attitude toward flood management in relation to risk perception and socio-economic factors. They conclude that WTP is higher for those who have high income and high level of risk perception.

There also exist some works that examine both WTP and WDL within a single framework yielding the same qualitative result, i.e., WTP (WDL) increases with income and education (Brown and Lankford, 1992, Bryant et al., 2003, Feldman, 2010, Cappellari et al., 2011, Bauer et al., 2013). However, we must note that the focus of these previous studies is on philanthropic activities, such as contributions to churches, in USA or European countries that differ from the Bangladeshi case of natural disasters in many aspects. In summary, many studies establish positive association between pro-sociality and income as well as between pro-sociality and education. Also, most of them employ a single option of either WTP or WDL to establish the result. More concretely, most CVM studies for valuing environmental goods use WTP (voluntary monetary payment), while other studies use either participation or labor donation in publicly organized programs or disaster mitigation. However, reflecting the reality facing Bangladeshi people, it is imperative to consider two channels of WDL (time) and WTP (money) for contributions to disaster mitigation.

This is motivated by the facts that labor donation is considered an integral part of sustainable disaster mitigation practices and many local people may not have money to donate, but they may 
still want to contribute their labor. Unfortunately, however, there have been no studies that consider the two options of donations within a single framework in the context of natural disasters and developing countries. Given this paucity, we seek to characterize pro-sociality toward disaster mitigation through examining both WDL and WTP. Doing so enables us to clarify the associations between WDL and income (education), between WTP and income (education), and the substitution between WDL and WTP with respect to income, education and others.

To this end, we conducted a questionnaire survey of approximately 1,000 respondents and elicited (i) WDL and (ii) WTP to collective countermeasures for avoiding the damage from cyclones and associated disasters. With this data, WDL and WTP are analyzed in relation to respondents' occupation, education and income. The novelty lies in offering respondents an option of choosing WTP and/or WDL in the questionnaire, considering the special circumstances of disaster mitigation and developing countries. The study finds that the poor and less educated people are likely to choose WDL and willing to donate more labor than money, while rich and educated people are likely to choose WTP and willing to donate more money than labor. However, we also find that voluntary labor donation from poor and less educated people is significant in that the overall donation from poor and less educated people exceeds that from rich and educated people. These results are in sharp contrast with the those of previous research. We conclude that poor and less educated people may be more pro-social toward natural disaster mitigation, and WDL is an important source of contributions to be utilized for the future disaster prevention and recovery in developing countries. We also believe that this result applies to more general cases because the results are consistent with observed labor donations in a case of the 2011 earthquake off the Pacific coast of Tohoku, Japan, suggesting the importance of labor donations in disaster mitigation and recovery.

\section{Cyclone AILA and our study region}

Bangladesh is the most vulnerable country to tropical storms and forceful cyclones (Government of Bangladesh, 2010). Dasgupta et al. (2010) note that the coastal area of Bangladesh is the most powerfully lethal zone among the top ten deadly ones in the world due to storm hazard and cyclones. 
Almost $10 \%$ of world's total tropical cyclones are generated in Bay of Bengal (Ali, 1996). From 1877 to 2009, 159 cyclones hit Bangladesh; 48 storms among them were very severe (Government of Bangladesh, 2010). Emanuel (2005) shows that the intensity and frequency of cyclones will increase in the future. High tidal rage, superficial continental and triangular shapes at the head of Bay are found to be the reasons for larger weights of storm surges in Bangladesh (Dasgupta et al., 2010). Since 1970, cyclones resulted in 450,000 deaths and prodigious amount of economic loss. Till date, cyclone AILA is the last super cyclone of category-1 which hit Bangladesh on May 25, 2009 (United Nation, 2010). Cyclone AILA was formed in Bay of Bengal on May 23, 2009 and was staying $350 \mathrm{~km}$ offshore. By the next two days it had been transformed and intensified to a very strong cyclone storm and hit the coastal region of Bangladesh. The speed of the wind was about 65-75 mph (Kumar et al., 2010). The economic damage and human sufferings are far higher than those from any other cyclone.

United Nation (2010) reports the following facts of damages associated with cyclone AILA. It initially caused approximately 7,100 injuries and 190 deaths, destroyed 1,742 $\mathrm{km}$ of embankment which led to a tidal flooding and washed away an immense number of households, livestock, standing crops, homestead-vegetables, and fisheries including shrimp-ghers. Moreover, 2,233 $\mathrm{km}$ and $6,621 \mathrm{~km}$ of roads were fully and partially damaged, respectively. Almost the total agricultural land and $80 \%$ of the livestock have been damaged. 9,712 ha of crop land was fully destroyed. As a result, most of the households had to sell their remaining livestock due to the scarcity of food. In the four severely affected upazilas ${ }^{2}$ of Satkhira and Khulna districts, namely Shyamnagar, Asasuni, Dacope, and Koira, almost $90-100 \%$ of the households were damaged (figure 1). Among 203,932 households, 201,000 ones faced the damage of their latrines and sanitation systems. Similarly, 13,000 tube-wells, 4,000 sweet water ponds, and 1,000 pond-sand filters were damaged which are the main sources of drinking water. The 445 education facilities were damaged, and 500,000 children lost their opportunities for education. People in the affected regions have suffered from a variety of diarrheal and skin diseases. Before cyclone AILA, the main livelihoods in these regions were fisheries and shrimp cultivation. However, during cyclone AILA, approximately 38,885 ha of sweet water

\footnotetext{
${ }^{2}$ Upazila is the second lowest administrative unit in Bangladesh.
} 
fisheries and shrimp-ghers were destroyed, and thus fishermen and shrimp-gher owners have lost their boat, had to sell their boat or given up their businesses for maintaining their daily cost of living and food security.

[Figure 1 about here.]

The major prolonged effect of cyclone AILA is the increased level of water and land salinity which is caused by the destruction of a whole embankment network. The demolition of embankment networks causes long time saline water stagnation and regular inundation of the saline water on the cultivable land. After cyclone AILA, it has been found that only a minor portion of the arable land is ready for cultivation due to regular inundation of saline water and the increased level of land and water salinity which causes a 70-80 percent loss of crop production. Similarly, due to this effect, shrimp cultivation productivity was reduced to $470.03 \mathrm{~kg} / \mathrm{ha}$ whereas it was 2,350 $\mathrm{kg} / \mathrm{ha}$ before AILA (United Nation, 2010). Nowadays, the people in these regions assume that due to the land and water salinity, it will take two more years in order for the land to be arable naturally for vegetable cultivation and six more years for fruit cultivation (Kumar et al., 2010).

During our survey even after four years of cyclone AILA, the farmers still said that the level of land and water salinity remains high. In addition, it has been reported that the farmers have cultivated rice for the first time after cyclone AILA in 2013 where our survey was conducted at the harvesting periods of the rice productions. The major source for the drinking water was the sweet water pond before cyclone AILA. Since the salinity level of the ponds has been increased, people in the affected areas still suffer from scarcity of drinking water (Shaha, 2014). All of safe water sources were inundated and affected by saline water. During the dry season in the affected areas of Khulna district, a household need to spend $16 \%$ of its monthly income only for sweet drinking water. These stories convey how long the negative impacts from cyclone AILA prolong.

Our study region is the two most severely affected areas or unions ${ }^{3}$ along with moderately affected union of Dacope upazila in Khulna district, namely, Kamarkhola, Sutarkhali and Tildanga, respectively (figure 1). Dacope upazila is located between $22^{\circ} 24^{\prime}$ and $22^{\circ} 40^{\prime}$ north latitudes and

\footnotetext{
${ }^{3} \mathrm{~A}$ union is the lowest administrative unit in Bangladesh.
} 
in between $89^{\circ} 24^{\prime}$ and $89^{\circ} 35^{\prime}$ east longitudes. The total land area of Dacope upazila is 991.58 $\mathrm{km}^{2}$ where total land area of Kamarkhola, Sutarkhali, and Tildnga is 7,214 acre, 12.092 acre, and 11,027 acre, respectively (Bangladesh Bureau of Statistics, 2011). In Bangladesh, the coastal area of Khulna and Satkhira districts are divided or separated into polders. Polders are embankmentbounded areas and this network of embankment protects these areas from storm surges. Kamarkhola and Sutarkhali unions are located in polder 32. These two unions are surrounded by river Shibsa and Dhaki in the west and north, in the east Sutarkhali, Chunkuri, and Bhadra (Bangladesh Water Development Board, 2013). Kamarkhola and Sutarkhali are the two mostly affected unions among the seventeen cyclone affected unions of Khulna and Satkhira districts, whereas Tildanga union is a less affected area. Based on United Nations Development Program (2009), in Dacope upazila, 94,000 people and 22,000 households were affected. 3,200 households and 16,000 people, 8,000 households and 40,000 people, and 8,000 households and 24,000 people were severely affected in Kamarkhola, Sutarkhali, and Tildanga, respectively. That implies that in Kamarkhola, Sutarkhali, and Tildanga, $90 \%, 100 \%$, and $80 \%$ of households were damaged.

\section{Data and methodology}

Our survey has been conducted in the selected regions between December 25, 2013 and January 5, 2014. In this survey, the twelve kinds of damages from cyclone storms were considered: 1. shelters, 2. schools and education, 3. roads, 4. embankment, 5. sanitation, 6. standing crop and food stock, 7. livestock, 8. shrimp-gher and fishery, 9. health, 10. fishing boat and net, 11. land quality due to salinity intrusion (land salinity), and 12. water quality due to salinity intrusion. These are the major damages caused by cyclone AILA in 2009, and the object of our valuation is collective disaster mitigation with a specific eye on cyclone AILA. The WDL and WTP for each damage have been elicited separately. One might consider that the valuation can be a private bad. However, a cyclone itself is a public bad and any type of cyclone disaster mitigation necessitates collective countermeasures that are considered non-excludable and non-rival in nature for avoiding the damages. Therefore, a valuation problem here is similar to valuing public or environmental 
goods, and we elicit respondents' WDL and/or WTP for each kind of cyclone damages itemized above.

We tried to be very specific about valuation questions to elicit WDL and WTP for each type of damages, because we realize that asking respondents to consider cyclone damages in an abstract way brings confusion and misunderstanding in our pilot survey. Therefore, the types of cyclone damages were specified and we chose to elicit the WDL and WTP for each, separately. First, we asked about each type of cyclone damages to respondents and then WDL and/or WTP for the corresponding possible countermeasures to avoid the damage. The countermeasures we specify in the valuation process are infrastructures or publicly organized programs such as building embankment networks. We also asked respondents to imagine that the WDLs and WTPs expressed in the survey shall be utilized or used for such infrastructures and publicly organized programs. The vehicle for eliciting WTPs (WDLs) to collective disaster mitigation is an extra fee per month (extra hours of voluntary labor per month), and we employ an open-ended question format. A series of these procedures basically follows Markantonis et al. (2013) and Ghanbarpour et al. (2014). ${ }^{4}$

The way of how we ask questions in our survey is determined by consulting with CVM experts and with the outcomes of our pilot survey prior to the "real" survey. In the pilot survey, the questionnaire was pretested by interviewing 70 respondents, and we refined the contents and wordings in the questionnaire. One unique feature is to give respondents the options to choose WDL and/or WTP as well as to specify their corresponding quantities. Respondents have four options to express their willingness to contribute: (1) WDL $>0$ and WTP $>0$, (2) WDL $>0$ and WTP $=0$, (3) WDL $=0$ and WTP $>0$, (4) WDL $=\mathrm{WTP}=0$. This idea is motivated by the fact that many local people may want to contribute labor rather than money to disaster mitigation or both. There have been no studies that elicit both WDL and WTP in the context of natural disaster mitigation although labor donations could be important. In the pilot survey, we have found that giving two options of WDL and WTP to respondents was effective.

\footnotetext{
${ }^{4}$ In fact, which elicitation format to use can be an issue in valuing public goods especially when respondents do not have any experience of "consuming" the public goods to formulate their preference. However, in our case, respondents have sufficiently experienced cyclones, storms and related disasters, and they did not have any difficulty expressing their willingness to contribute. In a similar type of situations, open-ended question formats have been used in previous studies (see, e.g., Markantonis et al., 2013, Ghanbarpour et al., 2014).
} 


\footnotetext{
${ }^{5}$ The survey questionnaire is in Bengali, but the translated version is available upon request.

${ }^{6}$ Union is the lowest administrative unit in Bangladesh and upazila is the second lowest administrative unit in Bangladesh.
} 
of samples by starting the survey from a different point within the sub-region.

One might wonder that a particular group of people, such as rich people, in these regions live only in a specific area. For example, rich and educated people might tend to live in some specific districts or residential areas in Europe, USA or Japan. However, this is not the case in the study regions. All types of people are well mixed and almost equally distributed over the districts. More specifically, a district, region, sub-region or village never consists of a specific type of people. In this light, we can say that natural disasters, such as cyclone AILA, are equally likely to affect people as a "public bad." Therefore, the data we obtained through this survey enables us to clarify how socioeconomic factors characterize pro-sociality of the local people toward collective disaster mitigation by considering WDL and WTP as contribution to public bads prevention and recovery. To analyze the survey data, we employ statistical and regression methods.

\section{Results}

\subsection{Socio-economic characteristics of respondents}

In this subsection, we summarize the socio-economic information of respondents focusing on occupation, education and household income. Regarding occupation, we categorize subjects into (0) day labor, (1) natural resource dependence, (2) farmer, (3) business, trade and service, and (4) shrimp-gher owner. "Day labor" respondents mainly work in construction industries or in small scale industries, depending on society's needs. During rice cultivation season, they also work as agricultural labor. Respondents at "natural resource dependence" comprise the fishermen, crab hunters, honey collectors, beekeepers and wood collectors. Respondents at "farmer" include those who engage in large, medium, or small scale farming activities. They own land or borrow it from others for cultivation. Respondents at "business, trade, and service" include all the businessmen, government and non-government service holders, middlemen in fishing business, and fishing boat owners. "Shrimp-gher owners" are those who cultivate shrimp in their own ponds which are called "gher." Table 1 shows the number of respondents that belong to each category of occupations. 
Regarding education, we categorize respondents into the following five categories: (0) illiterate (0 years of schooling), (1) primary (5 years of schooling), (2) secondary (10 years of schooling), (3) college (12 years of schooling) and (4) university (16 years of schooling). In the study region, most people do not go to colleges or universities. A majority of respondents are educated only up to secondary level. Combining the categorization with respect to occupation and education, table 1 summarizes the number of respondents that belongs to each level of education and each occupation. This table confirms that a majority of respondents are educated up to secondary level and work as “day labor," "natural resource dependence," and "farmer."

[Table 2 about here.]

[Figure 2 about here.]

We now examine respondents' household income with occupation and education. Figure 2(a) shows a boxplot of income distribution of respondents. The distribution is skewed with some outliers. The average income is 7,516 BDT/month, while the median is $6,000 \mathrm{BDT} / \mathrm{month}$ (see the cells of "income" rows and "overall" columns in table 2 where some other basic statistics of income distributions are shown). Figure 3(a) and the "income" rows of table 2 illustrate that day labor, natural resource dependence and farmer are low-income people, while businessmen and shrimp-gher owners are relatively rich in the region. In particular, shrimp-gher owners are the highest-income people, the second high-income is business, and following the order of farmer, natural resource dependence and day labor.

The second row of table 2 notes the average years of schooling per occupation by converting the category of education into years. It shows that people with high-income occupation tend to be more educated with an exception that shrimp-gher owners (5.68 years of schooling) are lesseducated than businessmen (7.68 years of schooling). To confirm this tendency between education and income, refer to "income" rows of table 3 and a boxplot of figure 4(a) illustrating that income becomes higher as education level rises. In summary, respondents at day labor, natural resource 
dependence and farmer are poor and less-educated, while those at business and shrimp-gher are rich and more educated.

[Figure 3 about here.]

[Figure 4 about here.]

[Table 3 about here.]

\subsection{Preliminary results on WDL and WTP}

\subsubsection{WDL and WTP}

We focus on reporting WDL and WTP for avoiding the overall cyclone damage. Here, WDL and WTP for avoiding overall cyclone damage means the summation of WDLs and WTPs expressed for each type of cyclone damages. Among 1,000 respondents 983 (98.3\%) respondents are willing to donate at least either money or labor for overall cyclone damage. Therefore, only 17 respondents (1.7\%) answer that both WDL and WTP are zero for all types of damages. Compared with other studies which elicit WTP for environmental or public goods, this response rate of strictly positive WDL and WTP is higher. The main reason may be that we offer respondents an option of choosing WDL and/or WTP for contribution to disaster mitigation. Among one thousand respondents, 109 respondents want to donate voluntary labor with zero WTP, 422 respondents go for both WDL and WTP. Finally, 452 respondents are willing to pay a positive amount of WTP without donating their labor.

[Table 4 about here.]

Table 4 presents the summary statistics of WDL and WTP per year for overall cyclone damage. The median for the WDL is 64.00 hours/year, while the mean is 112.21 hours/year. Also, the median for the WTP is $600.00 \mathrm{BDT} / \mathrm{year}$, while the mean is 1,099.51 BDT/year. From the statistics, we can see the clear difference between the means and the medians for each variable of WDL and WTP, suggesting the possibility that the WDL and WTP distributions may be non-normally 
distributed or skewed with possible outliers. To examine this, we run the normality Shapiro Wilk tests and draw boxplots using observed WTP and WDL data. The results of Shapiro-Wilk tests for WTP and WDL are summarized in table 5, demonstrating that they are not normally distributed. Figures 2(b) and 2(c) also show that they are skewed with outliers and not symmetrically distributed. Therefore, the boxplots and medians shall be used to represent the change in the distribution and the central tendency for analyzing and presenting the WDL and WTP results throughout the rest of our manuscript, because they are robust against non-normal and skewed distributions with outliers.

[Table 5 about here.]

\subsubsection{Aggregated WTP}

We compare WDL and WTP on the same ground by converting the individual WDL data to monetary terms with a minimum wage per hour (37.5 BDT per hour), and sum the "converted WDL" and WTP as "aggregated WTP." This "aggregated WTP" is calculated to clarify how people's overall willingness to contribute to disaster mitigation changes with key factors, irrespective of the channels for contribution. We are also motivated to see the importance of WDL relative to WTP in the total contribution. Recall that 17 respondents choose zero for both WDL and WTP, 109 respondents choose only WDL, 452 respondents choose only WTP, and 422 respondents choose both WDL and WTP for expressing their willingness to contribute.

Table 4 shows that the median and mean of aggregated WTP are 4,250 and 5,307 BDT/year, respectively, demonstrating that the distribution may be non-normal and skewed with possible outliers. Figure 2(d) confirms the existence of outliers and the distribution is non-normal and skewed. After WDL is converted into monetary terms and added to WTP, it is clear that WTP and aggregated WTP appear to have different distributions and statistics (see table 4, figures 2(c) and 2(d)). To confirm this, a quantile-quantile plot is drawn between WTP and aggregated WTP. Figure 5 illustrates that the distributions between the two are different and the distribution of aggregated WTP is mostly located above that of WTP. The result is consistent with figures 2(c) and 2(d), corroborating the considerable impact of WDL as a channel of contribution to collective disaster mitigation. 


\subsection{Pro-sociality toward disaster mitigation in relation to occupation, educa- tion and income}

In this subsection, we examine pro-sociality of WDL, WTP and aggregated WTP toward disaster mitigation in relation to occupation, education and income. More specifically, we examine how prosociality is related to the above factors.

\subsubsection{WDL}

In this subsection, we focus on WDL in relation to socio-economic characteristics. Our focus is on how WDL is related to occupation, education and income. The "WDL" rows of table 2 summarize the basic statistics per occupation. It shows clear heterogeneity of WDLs across occupations. In particular, business and shrimp-gher owners do not want to donate their labor, while day labor and farmer are willing to donate labor. Natural resource dependence is in-between the two groups. To graphically confirm this heterogeneity of WDL, we draw a boxplot for each type of occupation (figure 3(b)). This figure corroborates the fact that most respondents categorized as business and shrimp-gher owners do not want to donate their labor. Although some of business and shrimp-gher owners expressed to donate their labor, they are considered outliers in figure 3(b). On the other hand, a large proportion of respondents at day labor, natural resource dependence and farmer are willing to donate their labor much higher than those of business and shrimp-gher owners.

The "WDL" rows in table 3 present the summary statistics of WDL with respect to education levels. It shows that average and median WDLs generally decline with education levels. In particular, the median WDL is 0 for secondary, college and university levels of education. To confirm the declining tendency with respect to education levels, we draw the boxplot between WDL and education. Figure 4(b) demonstrates the monotonic declining trend of WDL as education levels rise. It should be noticed that a majority of WDLs consist of respondents with illiterate and primary level of education. This result is in sharp contrast with the previous research claiming that more educated 
people tend to contribute more of their time for charitable activities in Europe and USA.

Finally, we look at the relation between WDL and income. Figure 6 is a scatter plot between WDL and income illustrating some possibility of negative association. To test the negative association between WDL and income, we have run median regressions with the linear and linear quadratic specifications. Table 6 shows $1 \%$ significance level of negative association with respect to income, suggesting that monthly household income increases by 1000 BDT, WDL declines by 7.2 hours per year (model (1) in table 6). Model (2) in table 6 qualitatively shows the same result with model (1) with some non-linear effect of convexity. We also derive the unique turning point of income in model (2), that is, $22,916 \mathrm{BDT} / \mathrm{month}$. Unfortunately, the turning point can be considered an exceptionally high income based on the income distribution shown in figure 2(a). Therefore, the negative effect on WDL can be considered dominant for the meaningful range of respondents' income. Given the results of WDL in relation to occupation, education and income, it becomes clear that poor respondents with less-educated and more reliance on natural resource and climate are willing to donate their labor, while rich respondents with more education tend to provide less WDL or zero WDL.

[Figure 6 about here.]

[Table 6 about here.]

\subsubsection{WTP}

We now turn our attention to WTP in relation to occupation, education and income and seek to characterize the relation of WTP with these factors. The "WTP" rows of table 2 summarize the basic statistics in relation to occupation. This table shows that WTP increases in the order of day labor, natural resource dependence, farmer, business and shrimp-gher owner. The highest WTP occupation is shrimp-gher, the second is business, and the third, fourth and fifth are farmer, natural resource dependence and day labor, respectively. The boxplot of figure 3(c) also illustrates this point clearly. In the same way, the "WTP" rows of table 3 summarize the basic statistics with respect to education. As you can see from table 3, WTP appears to increase in education levels. Figure 4(c) demonstrates the increasing trend of WTP when education level of respondents rises. Recall that the occupation 
and education are closely related in the sense that respondents at business and shrimp-gher are more educated than those at day labor, natural resource and farmer (tables 1 and 2). Given this fact, we can say that WTP becomes higher as respondents are more educated and work as businessmen and shrimp-gher owners. Note that this tendency for WTP with respect to occupation and education is in sharp contrast with that for WDL.

[Figure 7 about here.]

We next analyze the relation between WTP and income. Figure 7 shows the scatter plot between WTP and income, suggesting some possibility of positive association. To confirm this, we run median regression and the result is presented in the columns "WTP" of table 6. The coefficient on income per month is statistically significant with $1 \%$ level and positive, irrespective of the linear and linear quadratic specifications. It implies that if monthly income increases by 1000 BDT, then the respondents may increase their WTP per year by 170 BDT in model (3) of table 6. However, recall that WDL is negatively associated with income, which is opposite with the relation between WTP and income identified in this subsection. Given the evidence that WDL and WTP respond to occupation, education and income in different directions, it is ambiguous that overall contribution from people toward disaster mitigation declines or rises with education and income levels or it may be non-linear. Therefore, we look at the relation between aggregated WTP and socio-economic factors.

\subsubsection{Aggregated WTP}

Given the fact that WDL and WTP respond to socio-economic factors in the opposite directions, we now examine aggregated WTP which is the sum of monetized WDL and WTP. ${ }^{7}$ The "aggregated WTP" rows of table 2 show the basic statistics with respect to occupation. Surprisingly, aggregated WTP is the highest in day labor, the second highest is farmer, and the third, fourth and fifth are natural resource dependence, shrimp-gher owner and business, respectively. Figure 3(d) demonstrates that the distributions for the types of occupation follow the same tendency. We did not expect this

\footnotetext{
${ }^{7}$ Monetized WDL means the value computed by converting WDL into money with a minimum wage that prevails in Bangladesh (37.5 BDT/hour).
} 
result due to the fact that respondents at day labor, farmer and natural resource dependence are those who are less educated and not wealthy. Based on our initial expectation and previous research on philanthropic activities, this implies that they must be busy with their own life for food and survival. Thus, they should not have much motivation for donating their time and money. Furthermore, the cyclone damage they suffer should not be large since they do not have assets and wealth. We also conjectured that respondents at business and shrimp-gher would have contributed much more than the results suggest. In this sense, our initial expectation regarding the results of aggregated WTP is totally betrayed.

The "aggregated WTP" rows of table 3 summarize the basic statistics with respect to education. Contrary to the cases of WDL and WTP, we can see that the change in aggregated WTP is not monotonic as education level increases. It is the highest in illiterate, hits the bottom at secondary and increases again at college and university. Recall that WDL (WTP) decreases (increases) with education. Combining these two, our non-monotonic result on aggregated WTP with respect to education is quite convincing. Figure 4(d) also illustrates that the distributions of aggregated WTPs are higher for respondents with illiterate and primary level of education, the distribution becomes lowest for secondary, but it becomes higher again for college and university. In summary, aggregated WTP changes with education levels in a non-monotonic U-shape manner.

[Figure 8 about here.]

Finally, we look at the relation between aggregated WTP and income. Figure 8 presents a scatter plot between aggregated WTP and income, suggesting no clear association between the two. To check the relation, we again run the median regression and the results are shown in columns (5) and (6) of table 6. The results suggest that aggregated WTP initially declines as income rises. However, the positive coefficient on the income square term with $1 \%$ significance implies that there is a turning point of 18,750 (BDT/month) above which the overall effect turns to be positive. In fact, we identify that there are only 41 respondents whose household income is above 18,750. Therefore, the negative effect of income appears to be dominant on aggregated WTP for most meaningful range of respondents' income. Overall, our results on aggregated WTP are opposite to the results of 
previous research on philanthropic activities, although there are some common features.

\section{Discussion and conclusion}

This paper has studied pro-social behavior toward disaster mitigation by considering an important case of cyclone AILA in Bangladesh. One novel feature is that we incorporate the two options of WDL and WTP when we ask respondents to express their willingness to contribute to the collective countermeasure against cyclone damage. To identify WDL and WTP, we ask what type of cyclone damages each respondent suffers and how much he/she wants to contribute. To our knowledge, this is the first study that considers WDL and WTP within a single framework to analyze pro-social behavior in the context of disaster mitigation and developing countries. We are motivated to do so because voluntary labor donation is an important input for collective prevention and recovery in the context of disaster mitigation. To establish our results, some statistical and regression analysis is applied, considering the fact that elicited WDL and WTP are non-normally distributed and highly skewed with several outliers. Therefore, we consistently rely on graphical statistical tools and median regressions, because they are robust in such a situation.

Several new findings must be noted. First, those whose occupations are day labor, natural resource dependence, and farmer are likely to choose WDL. This also implies that poor and lesseducated people tend to choose WDL and to express their willingness to contribute more to disaster mitigation through the channel of WDL. On the other hand, rich and more-educated people at business and shrimp-gher are likely to choose WTP and to express their willingness to contribute through the channel of WTP. These results reflect the asymmetric responses of WDL and WTP to education and income. Thus, we consider aggregated WTP (sum of the monetized WDL and WTP) to clarify how overall contribution changes with socio-economic factors, irrespective of the channels of WDL and WTP. We find that aggregated WTP tends to decline as education level and income rise, because the contribution of WDL is significant. Although there is a possibility of non-monotonic U-shaped effect of income on aggregated WTP, we identify that the turning point of income above which the effect turns to be positive is not practically meaningful for the income range of most respondents. 
Therefore, the possible positive effect that may come from non-linear effects of income appears to be minute in our case.

Past literature focuses on charitable activities to study pro-social behavior of people and their cases are taken from European countries and USA. The qualitative results are opposite to ours in that more educated and rich people tend to donate more labor and money to charitable activities. To explain the difference of our results, we have to emphasize some unique features in this study. Our research conducted the questionnaire survey in the very poor region of a developing country, Bangladesh, and the region is known to suffer from frequent natural disasters such as cyclones, storm surges and so on. This unique setup of our questionnaire survey may be the reason that our initial expectation was betrayed by the results. That is, poor and less-educated respondents want to contribute WDL much more than we expected. As a consequence, aggregated WTP declines as education or income level increases. As mentioned in introduction, collective disaster mitigation is urgent in the study region, and thus voluntary contribution from local people is an integral part of this implementation and its sustainability. Unfortunately, public mitigation programs that collect and organize WDL and WTP from people are not well established in the regions. Considering the fact that a majority of respondents expressed to contribute in this research, there should be some possibility of successful development for sustainable and collective disaster mitigation practices by fully utilizing the WDL and WTP.

An important question that naturally arises from the results is: Why do poor and less-educated people want to donate their labor in a way much more than rich and educated people donate money? A first argument is that they simply have more time to contribute compared with businessmen and shrimp-gher owners. This could be explained by utility maximization of time allocation problems under the assumption that their labor donation gives sufficient benefit to themselves compared to wage earnings and other activities. However, these people are those who do not have many assets and much wealth that can be the objects of losses when natural disasters hit the area. In other words, they do not have anything to lose, because they are very poor. Thus, we expected that they should not be motivated to contribute. However, we now think that our initial expectation built upon this logic is not correct. Another possible explanation is that poor and less-educated people are more 
pro-social. This argument is claimed by several psychologists and sociologists. We also support this argument, because we asked poor and less educated respondents the motivation of why they want to donate labor. Most of their answer to this question is that they believe an improvement of local society and expand the possibility of better environment for their children by donating their labor. It appears that their answers represent higher degree of pro-sociality than rich and more educated respondents. Unfortunately, however, further research shall be needed to rigorously support this line of arguments.

Finally, we have to note some limitations of our study. First, we relied on eliciting hypothetical WDL and WTP as other CVM research does. This is due to the fact that there are no publicly organized programs or entities that collectively utilize voluntary labor and donated money for disaster management in the study region. Therefore, it is impossible to observe "actual" WDL and WTP behaviors. Related to this hypothetical nature of the WDL and WTP data, we have to admit the existence of possible hypothetical biases. These caveats notwithstanding, the hypothetical biases for WDL and WTP are expected to be rather small, because respondents are those who have experienced frequent natural disasters, in particular, cyclones and storms, and could answer the WDL and WTP without any difficulty.

It is our belief that the qualitative results drawn from this field study of natural disaster mitigation apply to more general cases, and suggest another direction of research with respect to the relation between WDL and WTP to develop publicly organized disaster mitigation. In particular, our results are quite consistent with observed pro-social behaviors of people in the 2011 earthquake off the Pacific coast of Tohoku, Japan. In this case, labor donation is confirmed to be important and contributes significantly to the disaster recovery as well. Although it has never been examined scientifically, it appears that people who donated their labor in the case of 2011 Tohoku earthquake are neither rich nor educated compared to the average Japanese people. This consistency between our study and the Japanese case would suggest a new horizon of research for voluntary contribution to disaster management. 


\section{Bibliography}

Alberini, A. and Kahn, J. R., editors (2009). Handbook on contingent valuation. Edward Elgar.

Ali, A. (1996). Vulnerability of Bangladesh to climate change and sea level rise through tropical cyclones and storm surges. Water, air, and soil pollution, 92(1-2):171-179.

Bangladesh Bureau of Statistics (2011). District statistics, Khulna, 2011.

Bangladesh Water Development Board (2013). Resettlement action plan, volume II.

Bauer, T. K., Bredtmann, J., and Schmidt, C. M. (2013). Time vs. money-The supply of voluntary labor and chritatable donations across Europe. European journal of political economy, 32:80-94.

Bienabe, E. and Hearne, R. R. (2006). Public preferences for biodiversity conservation and scenic beauty within a framework of environmental services payments. Forest policy and economics, 9(4):335-348.

Brechin, S. R. and Kempton, W. (1994). Global environmentalism: A challenge to the postmaterialism thesis? Social science quarterly, 75(2):245-269.

Brown, E. and Lankford, H. (1992). Gifts of money and gifts of time: Estimating the effects of tax prices and available time. Journal of public economics, 47:321-341.

Bryant, W., Jeon-Slaughter, H., Kang, H., and Tax, A. (2003). Participation in philanthropic activities: Donating money and time. Journal of consumer policy, 26:43-73.

Cappellari, L., Ghinetti, P., and Turati, G. (2011). On time and money donations. Journal of socioeconomics, 40:853-867.

Carson, R. T., Mitchell, R. C., Hanemann, M., Kopp, R. J., Presser, S., and Ruud, P. A. (2003). Contingent valuation and lost passive use: Damages from the Exxon Valdez oil spill. Environmental and resource economics, 25(3):257-286.

Cooper, P., Poe, G. L., and Bateman, I. J. (2004). The structure of motivation for contingent values: A case study of lake water quality improvement. Ecological economics, 50:69-82.

Dasgupta, S., Huq, M., Khan, Z. H., Ahmed, M. M., Mukherjee, N., Khan, M. F., and Pandey, K. (2010). Vulnerability of Bangladesh to cyclones in a changing climate: Potential damages and adaptation cost. Policy research working paper 5280, The World Bank.

Dorcey, A. H. J. and McDaniels, T. (2001). Great expectations, mixed results: Trends in citizen involvement in Canadian environmental performance. In Governing the environment. Toronto university press.

Emanuel, K. (2005). Increasing destructiveness of tropical cyclones over the past 30 years. Nature, 436(7051):686 - 688 .

Feldman, N. E. (2010). Time is money: Choosing between chartitable activities. American economic journal: Economic policy, 2(1):103-130. 
Freeman, R. B. (1997). Working for nothing: The supply of volunteer labor. Journal of labor economics, 15(1):S140-S166.

Frey, B. S. and Meier, S. (2004). Pro-social behavior in a natural setting. Journal of economic behavior and organization, $54: 65-88$.

Ghanbarpour, M., Saravi, M. M., and Salimi, S. (2014). Floodplain inundation analysis combined with contingent valuation: Implications for sustainable flood risk management. Water resources management, 28:2491-2505.

Godschalk, D. R., Bordy, S., and Burby, R. (2003). Public participation in natural hazard mitigation policy formation: Challenges for comprehensive planning. Journal of environmental planning and management, 46(5):733-754.

Government of Bangladesh (2010). National plan for disaster management 2010-2015. Technical report, Government of Bangladesh.

Himelein, K., Eckman, S., and Murray, S. (2014). Samplign nomads: A new technique for remote, hard-to-reach and mobile population. Journal of official statistics, 30(2):191-213.

Kemmelmeier, M., Krol, G., and Kim, Y. H. (2002). Values, economics, and proenvironmental attidues in 22 societies. Cross-cultural research, 36:256-285.

Khan, T. M. A., Singh, O. P., and Rahman, M. S. (2000). Recent sea level and sea surface temperature trends along the Bangladesh coast in relation to the frequency of intense cyclones. Marine geodesy, 23(2): 103 - 116 .

Kontogianni, A., Skourtos, M. S., Langford, I. H., Bateman, I. J., and Georgiou, S. (2001). Integrating stakeholder analysis in non-market valuation of environmental assets. Ecological economics, 37(1):123-138.

Kumar, U., Baten, M. A., Masud, A. A., Osman, K. S., and Rahman, M. (2010). Cyclone AILA: One year on natural disaster to human sufferings. Technical report, Unnayan Onneshan.

Luo, X. and Levi, A. E. (2013). Factors influencing willingness to participate in disaster reduction. Natural hazards, 66(2):1243-1255.

Markantonis, V., Meyer, V., and Lienhoop, N. (2013). Evaluation of the environmental impacts of extreme floods in the Evros river basin using contingent valuation method. Natural hazards, 69(3):1535-1549.

Martin-Ortega, J., Brouwer, R., and Aiking, H. (2011). Application of a value-based equivalency method to assess environmental damage compensation under the European environmental liability directive. Journal of environmental management, 92(6):1461-1470.

Menchik, P. L. and Weisbrod, B. A. (1987). Volunteer labor supply. Journal of public economics, 32:159-183.

Mileti, D. (1999). Disasters by design: A reassessment of natural hazards in the United States. Joseph Henry Press. 
Mitchell, R. C. and Carson, R. T. (1988). Using surveys to value public goods: The contingent valuation method. RFF Press.

Pearce, L. (2003). Disaster management and community planning and public participation: How to achieve sustainable hazard mitigation. Natural hazards, 28:211-228.

Plagnol, A. C. and Huppert, F. A. (2010). Happy to help? Exploring the factors associated with variations in rates of volunteering across Europe. Social indicators research, 97:157-176.

Shaha, P. S. (2014). The cost of drinking water in the coast is even higher than that of Dhaka city. Daily Prothom Alo. In Bengali.

Singh, O. P., Kahn, T. M., and Rahman, M. (2001). Has the frequency of intense tropical cyclones increased in the north Indian Ocean? Current science, 80(4):575-580.

Smith, D. H. (1994). Determinants of voluntary association participation and volunteering: A literature review. Nonprofit and voluntary sector quarterly, 23:243-263.

Torgler, B., Frey, B., and Wilson, C. (2009). Environmental and pro-social norms: Evidence on littering. The B.E. journal of economic analysis \& policy, 9(1):1-39.

United Nation (2010). Cyclone AILA: Joint UN mutlisector assessment and response framework. Technical report, United Nation.

United Nations Development Program (2009). Field visit report on selected AILA affected areas. Technical report, United Nations Development Program.

Vanslembrouck, I., Van Huylenbroeck, G., and Verbeke, W. (2002). Determinants of the willingness of Belgian farmers to participate in agri-environmental measures. Journal of agricultural economics, 53(3):489-511.

Wolff, N., Weisbrod, B. A., and Bird, E. J. (1993). The supply of volunteer labor: The case of hospitals. Nonprofit management and leadership, 4(1):23-45. 


\section{List of Tables}

$617 \quad 1$ The number of respondents with respect to occupation and education . . . . . . . 28

$618 \quad 2$ Income, WDL, WTP, and aggregated WTP with respect to occupation . . . . . . . 29

6193 Income, WDL, WTP and aggregated WTP with respect to education . . . . . . . 30

6204 Summary statistics of WDL, WTP and aggregated WTP for overall cyclone damage 31

6215 Shapiro-Wilk tests of WTP and WDL for overall damage . . . . . . . . . . . 32

6226 Median regressions of WDL, WTP and aggregated WTP with respect to income . . 33 


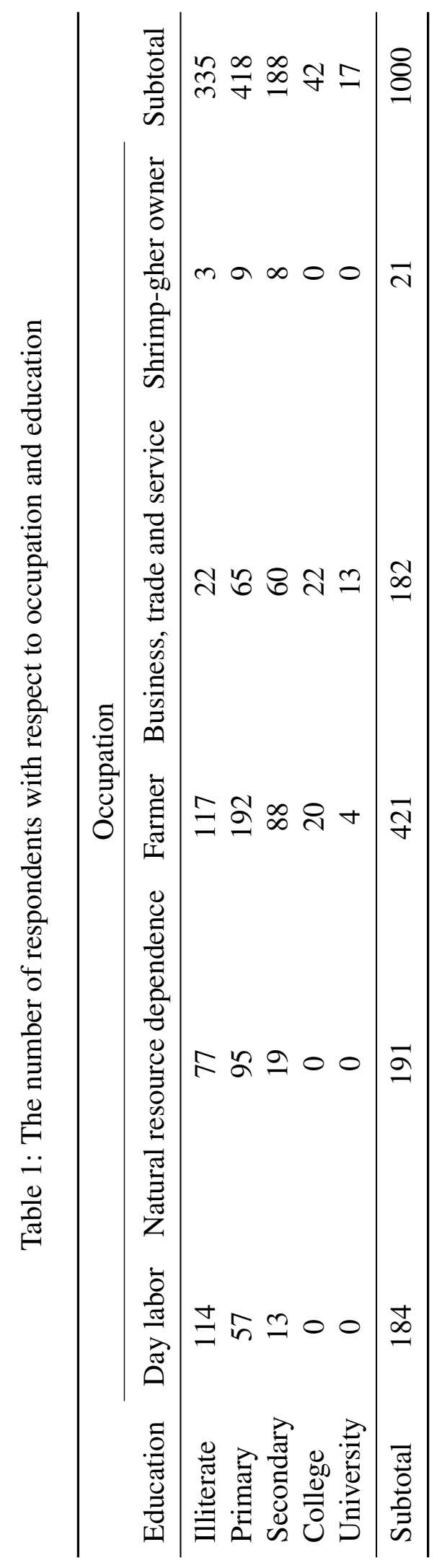




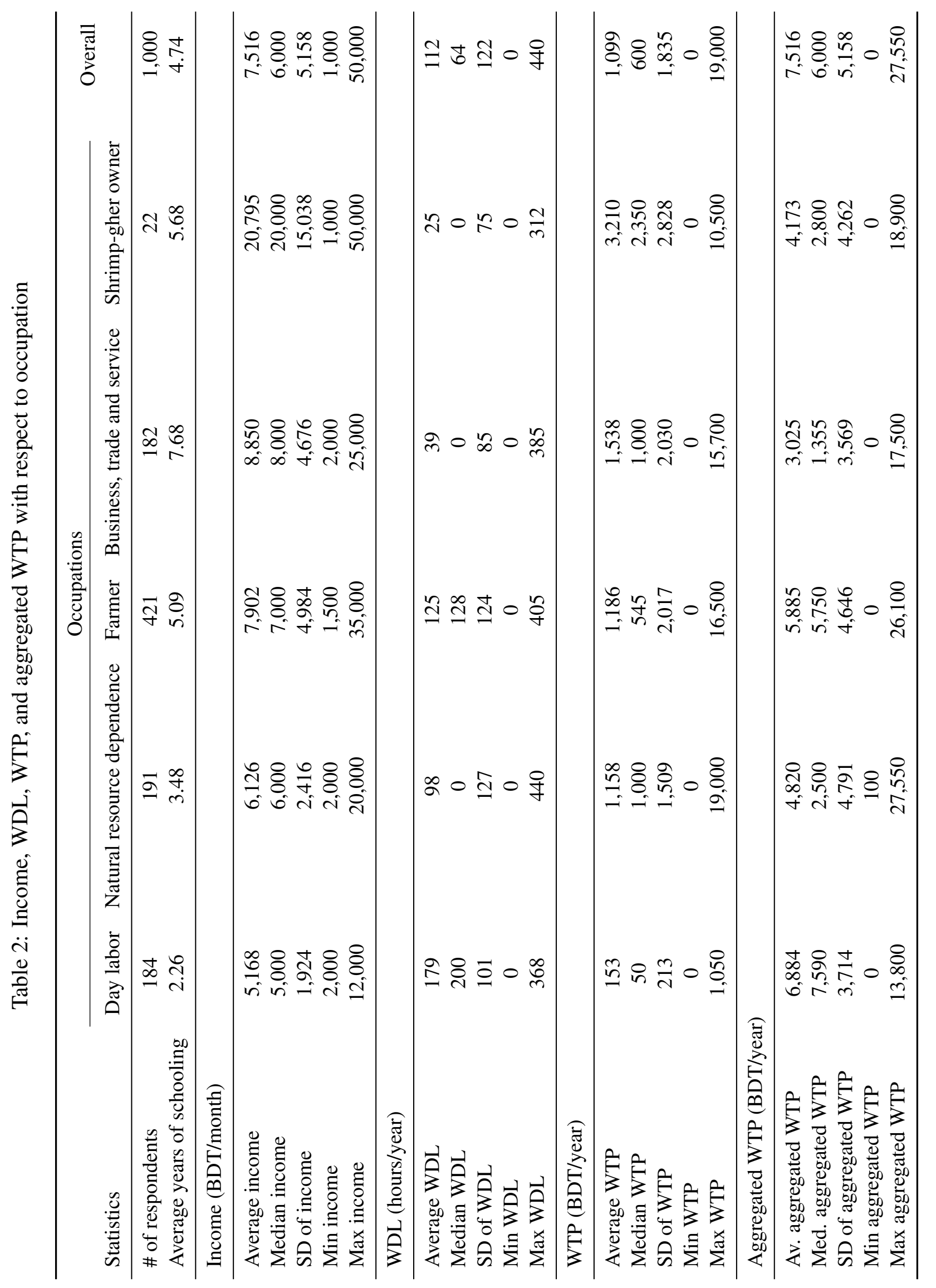




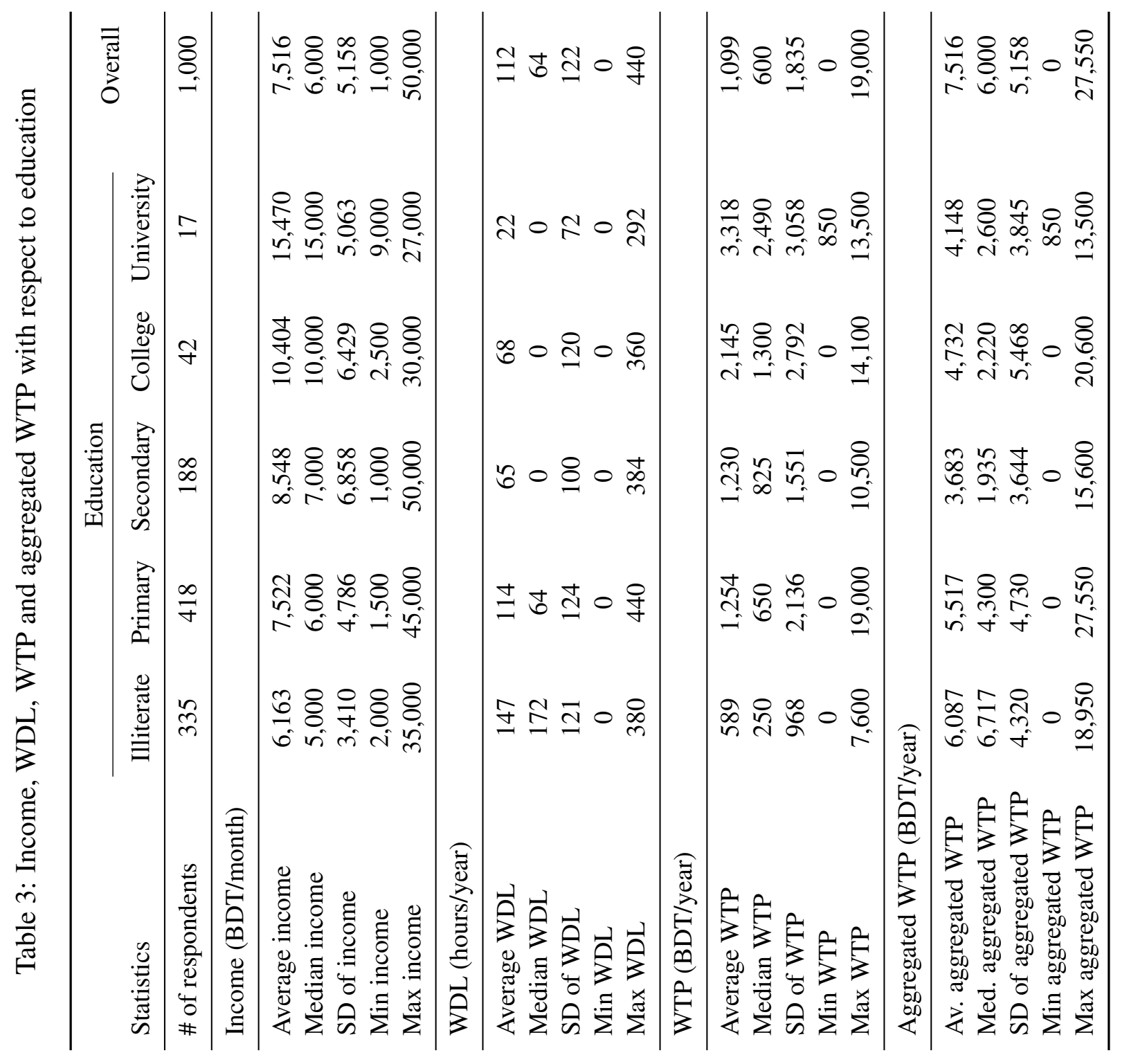




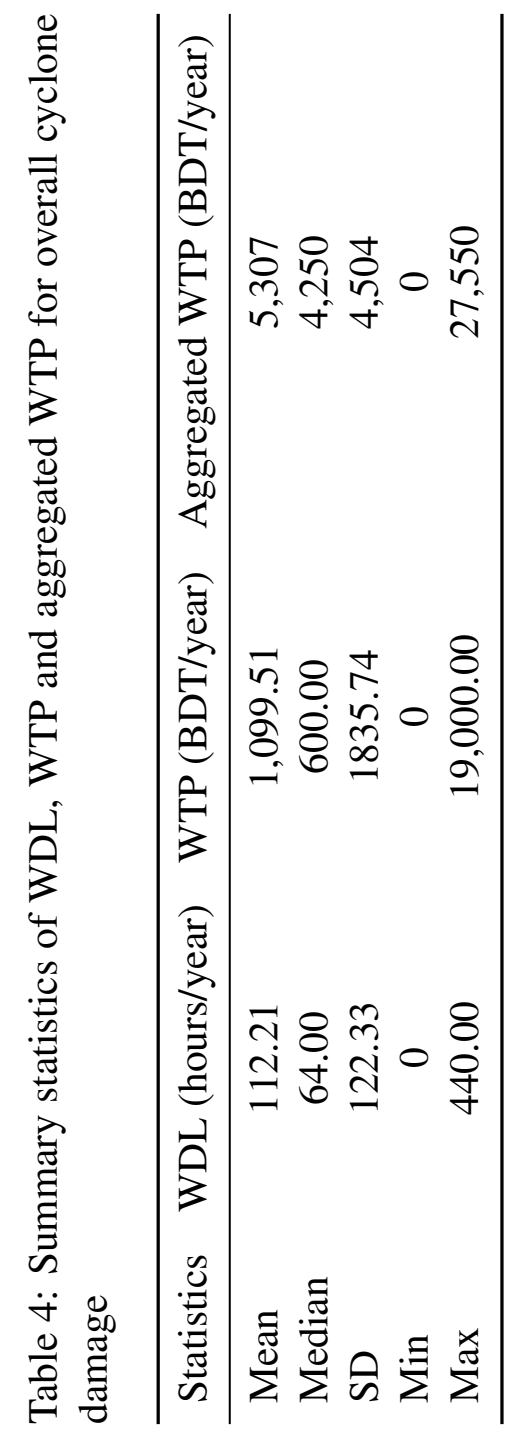




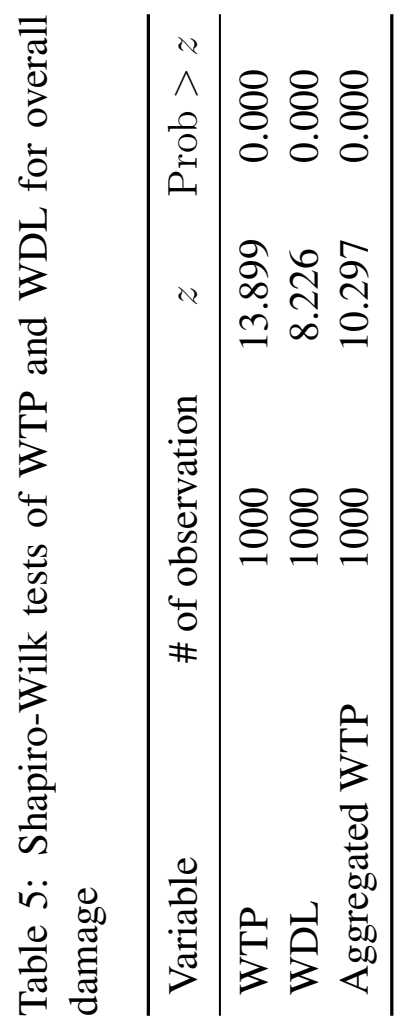




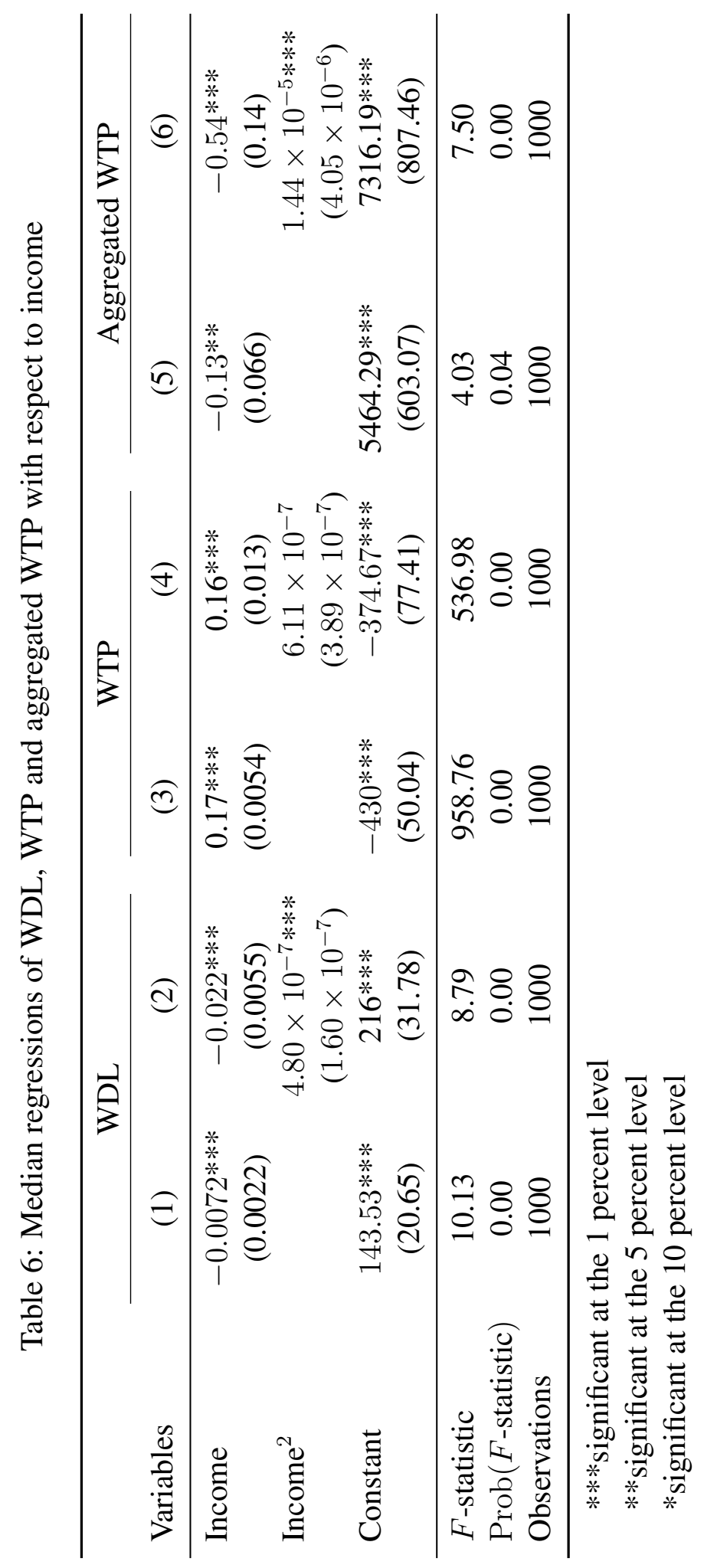


${ }_{623}$ List of Figures

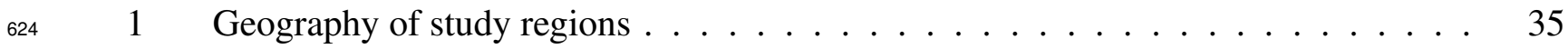

6252 Boxplots of income, WDL, WTP and aggregated WTP $\ldots \ldots \ldots \ldots \ldots$

3263 Boxplots of income, WDL, WTP and aggregated WTP for occupation . . . . . . 37

${ }_{627} 4$ Boxplots of income, WDL, WTP and aggregated WTP for education . . . . . . . 38

${ }_{628} 5$ Quantile-quantile plot between WTP and aggregated WTP $\ldots \ldots \ldots \ldots \ldots$

6296 Scatter plot between WDL and income . . . . . . . . . . . . . . . 40

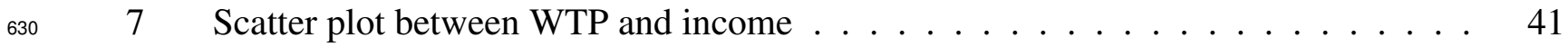

${ }_{631} \quad 8 \quad$ Scatter plot between aggregated WTP and income . . . . . . . . . . . . . . 42 


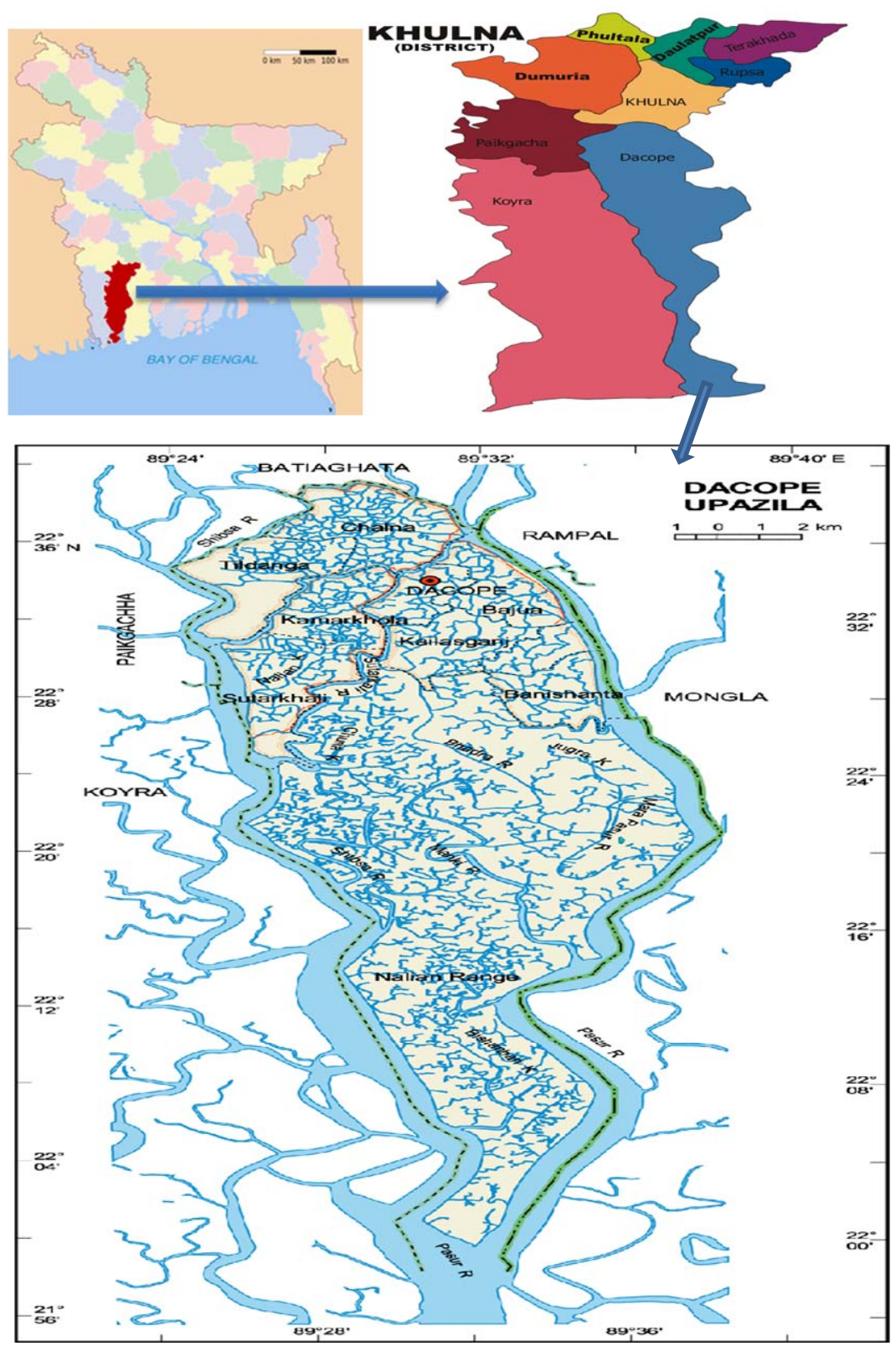

Figure 1: Geography of study regions 

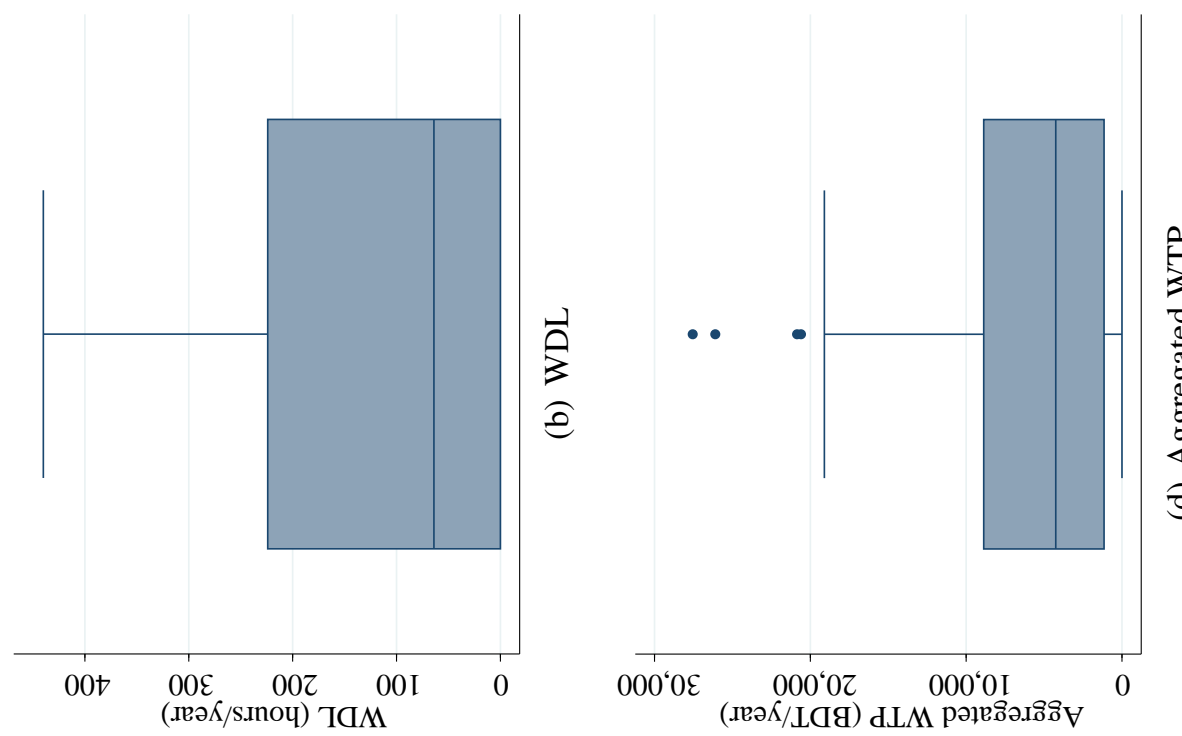

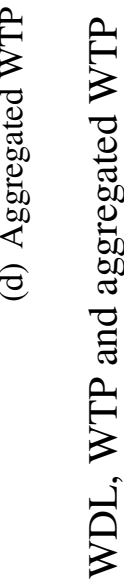
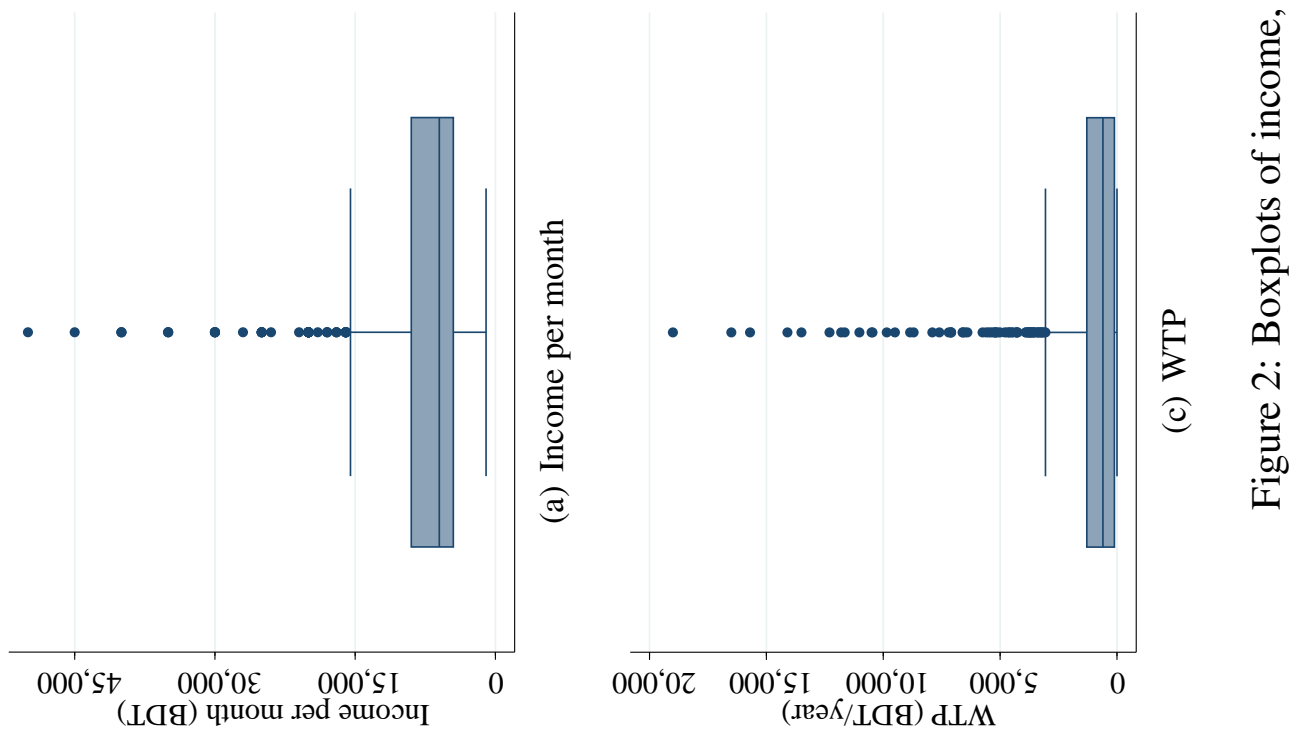


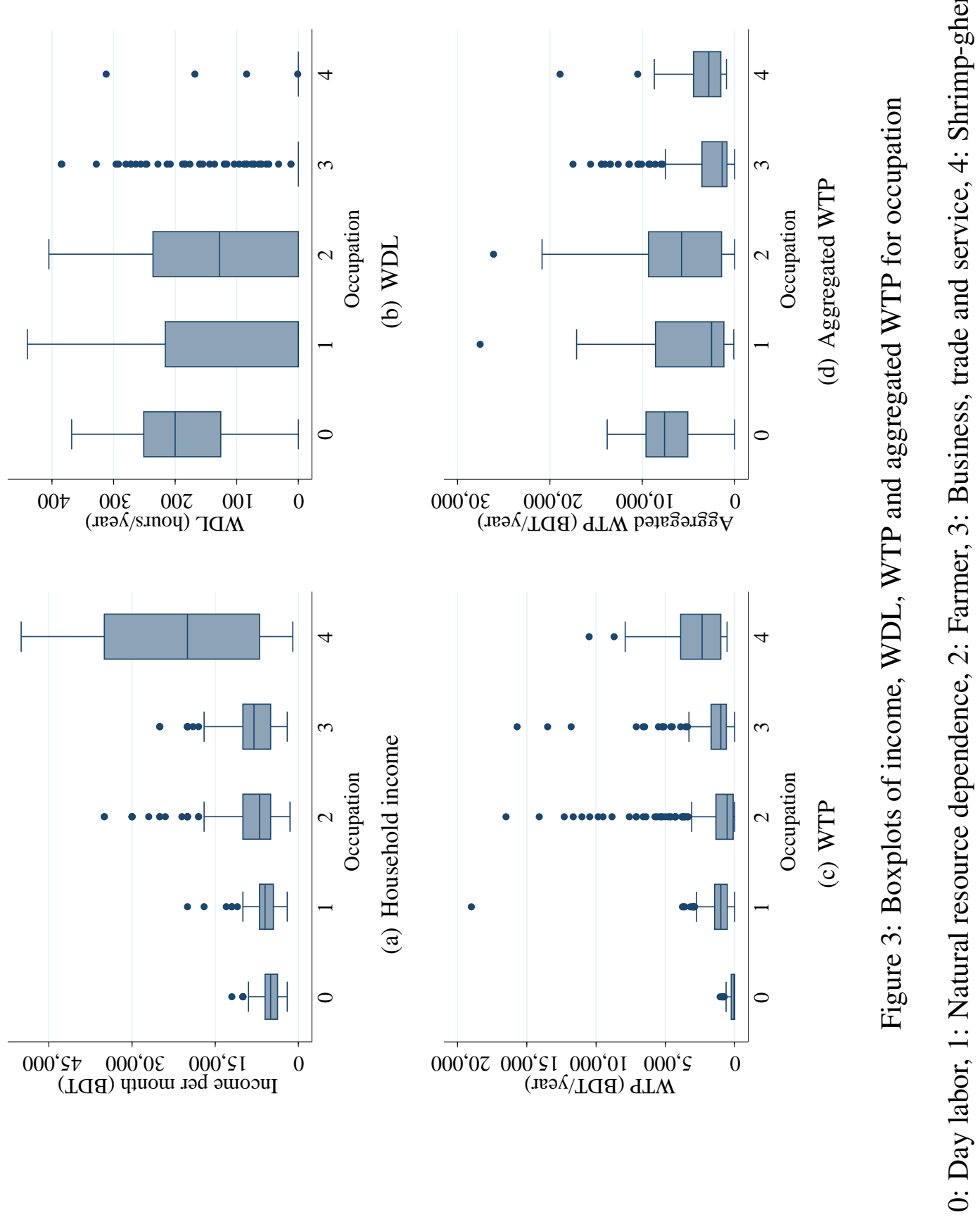



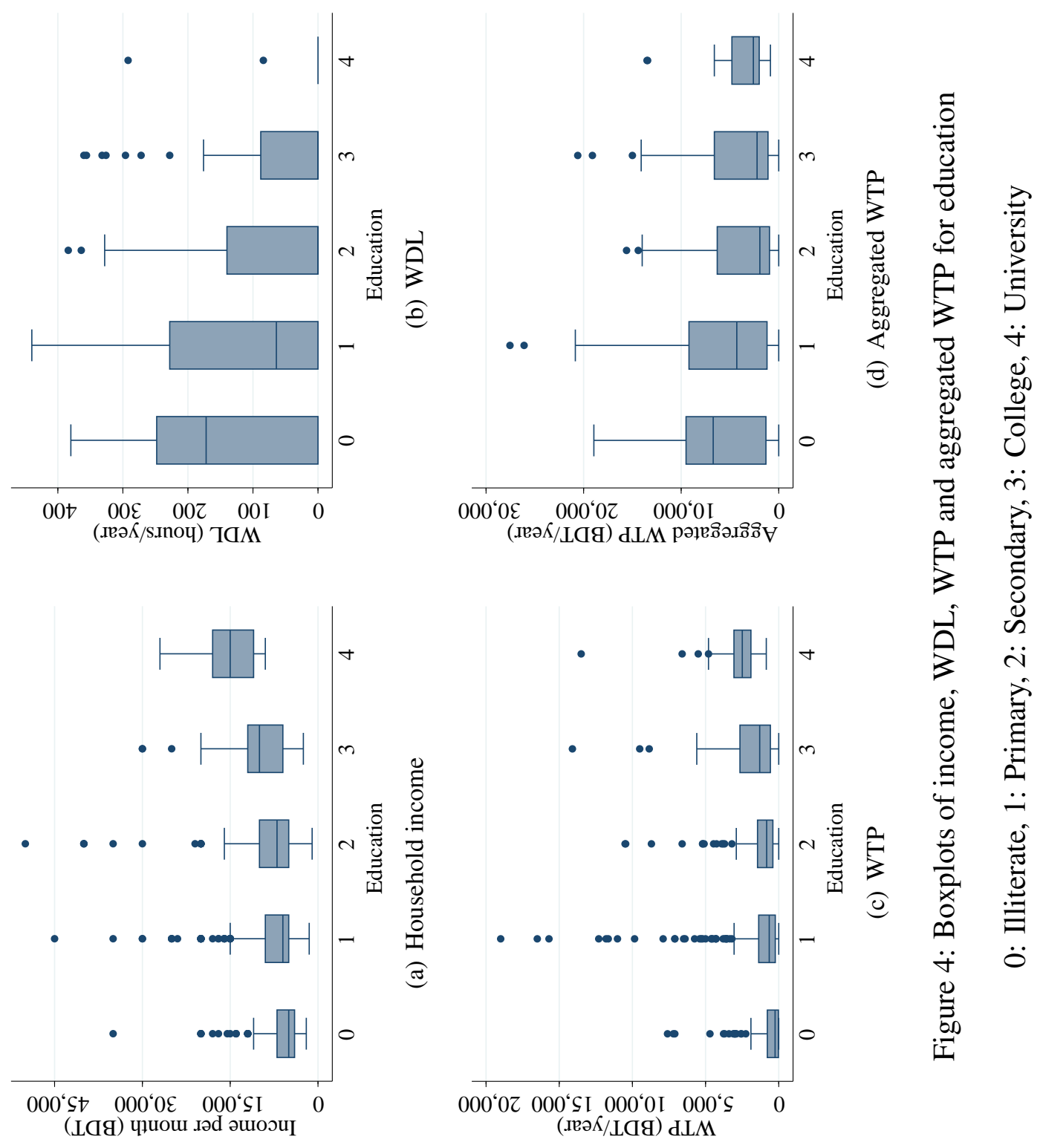


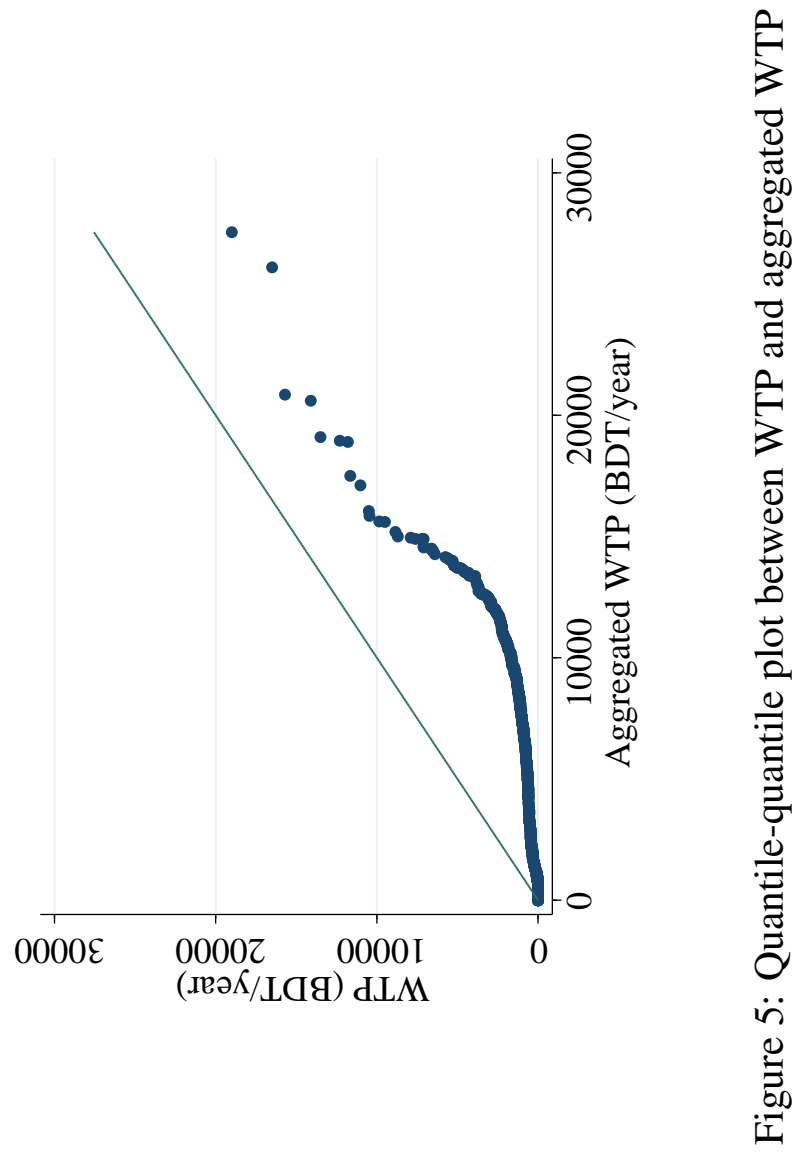




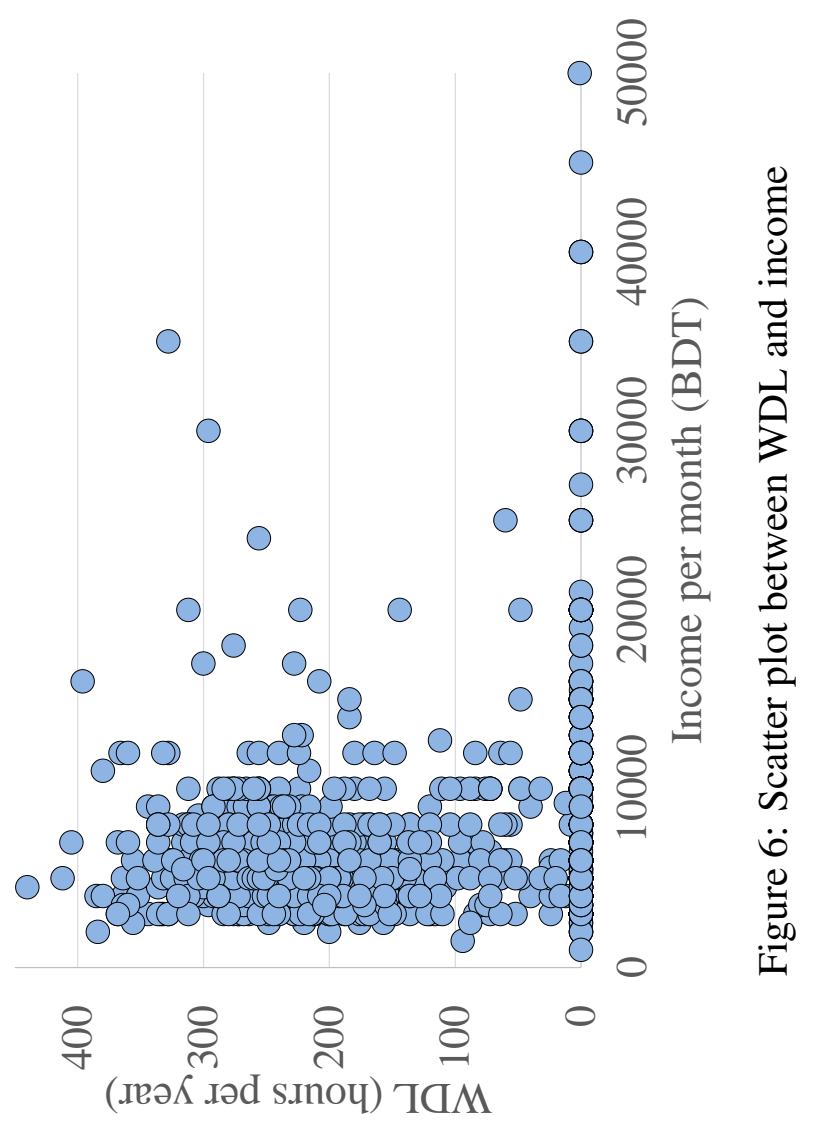




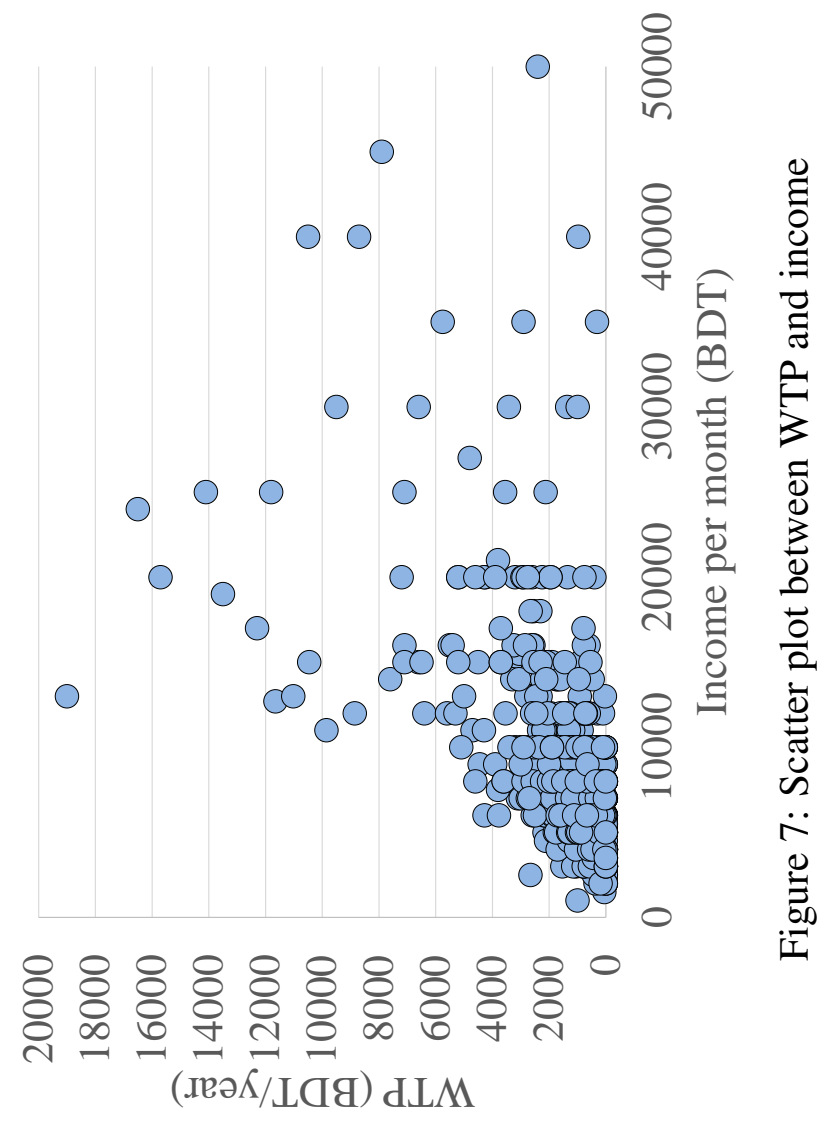




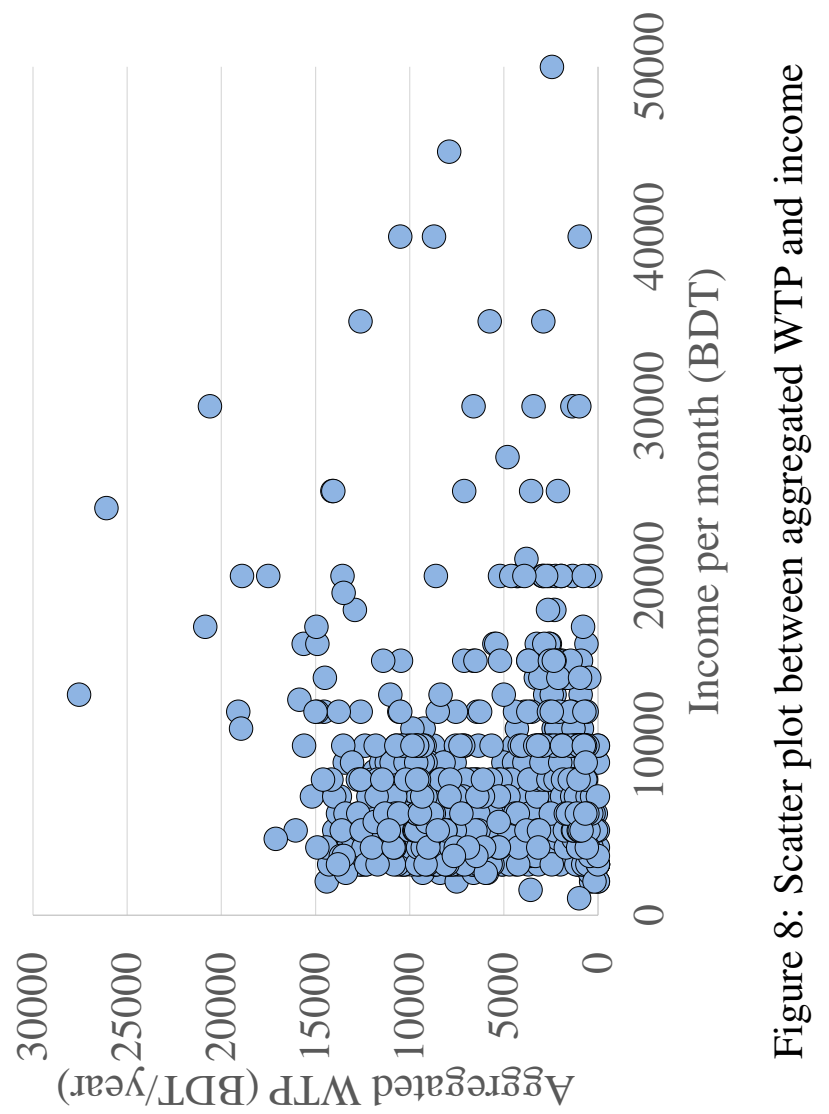

